\title{
The moisture content and opening of serotinous cones from lodgepole pine killed by the mountain pine beetle
}

\author{
by Maria Sharpe ${ }^{1,2}$ and Soung Ryoul Ryu ${ }^{1 *}$
}

\begin{abstract}
The aging lodgepole pine forests of Western Canada have become increasingly susceptible to insect and disease outbreaks. This is evident by the rise of mountain beetle (MPB) populations in British Columbia and Alberta. Serotinous cones of lodgepole pine require heat to open and the moisture content $(\mathrm{MC})$ of cones is considered to influence the opening process. However, little is known about how tree conditions (live and dead) may affect this process. We evaluated the effects of MPB-killed trees and cone age on (1) cone MC, (2) moisture exchange, and (3) time required to open a cone after exposure to heat. The results showed active moisture exchange into and out of closed cones from both live and dead trees. Cone $\mathrm{MC}$ was not a main driving factor determining the time for opening the cones. Cones from dead trees had higher mean moisture content (MC), higher $\mathrm{MC}$ variation and took a longer time to open than those from live trees, presumably decreasing the potential for scorching of seed supply. This indicates that seeds in cones of MPB-killed stands may be better able to survive a fire than those of live trees.
\end{abstract}

Key words: serotinous cones, mountain pine beetle, forest fire, cone moisture, cone opening, forest management.

\section{RÉSUMÉ}

Les forêts vieillissantes de pin lodgepole de l'ouest du Canada sont de plus en plus susceptibles aux épidémies d'insectes et aux ravages des maladies. La preuve en est laugmentation des populations de dendroctone du pin en Colombie-Britannique et en Alberta. Les cônes sérotineux du pin lodgepole requièrent de la chaleur pour pouvoir souvrir et le taux d'humidité (TH) des cônes est considéré comme ayant une influence sur le processus douverture. Cependant, peu de choses sont connues sur létat des arbres (vivants et morts) qui pourrait influencer le processus. Nous avons évalué les effets répertoriés sur des arbres ravagés par le dendroctone du pin et lâge des cônes au niveau (1) du TH des cônes, (2) des échanges d'humidité et (3) du temps requis pour que souvre le cône après une exposition à la chaleur. Les résultats ont démontré des échanges actifs d'humidité vers l'intérieur et vers l'extérieur dans les cônes fermés tant chez les arbres vivants que morts. Le TH des cônes n’a pas été un facteur déterminant du moment de louverture des cônes. Les cônes d’arbres morts affichaient un taux d'humidité (TH) moyen supérieur, une plus grande variation du TH et ont pris plus de temps à souvrir par rapport aux arbres vivants, permettant probablement de réduire la possibilité que les graines soient brûlées. Cela démontre que les graines des cônes issus de peuplements ravagés par le dendroctone du pin pourraient être en meilleur position pour survivre à un feu de forêts que celles provenant d’arbres vivants.

Mots clés : cônes sérotineux, dendroctone du pin, feu de forêt, humidité des cônes, ouverture des cônes, aménagement forestier

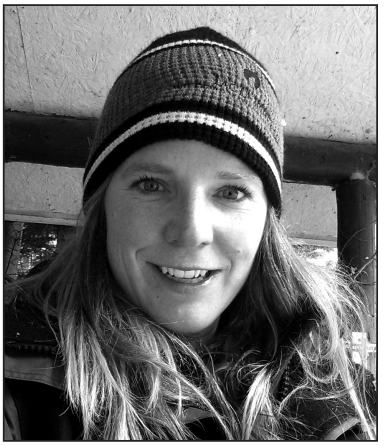

Maria Sharpe

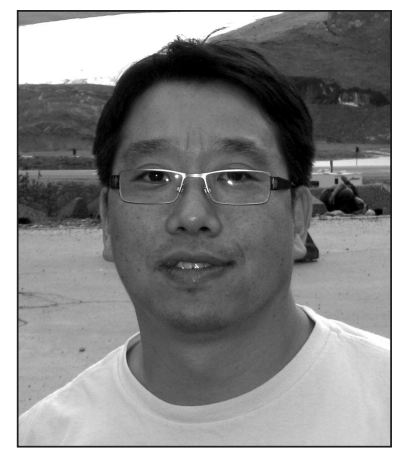

Soung Ryoul Ryu

\section{Introduction}

Lodgepole pine (Pinus contorta Dougl. ex Loud. var. latifolia Engelm.) is a dominant tree species in Canada, composing $20 \%$ of the country's total coniferous growing stock (four bil-

lion $\mathrm{m}^{3}$ ) (https://www.albertacanada.com/files/albertacanada/ AIS-BP_LodgepolePine.pdf). Its dominance is mainly owing to its adaptation strategy (e.g., high seed and serotinous cone production) to wildland fire, which is a common disturbance factor in Canadian boreal forests (Lotan 1976, Teste et al. 2011a). The scales of serotinous cones are sealed by resinous bonds which break after exposure to heat from fire or direct sunlight through an open canopy. This often results in high seedling density after a fire event (Tower 1909, Clements 1910, Crossley 1956). Furthermore, serotinous cones significantly improve the longevity of seed viability up to 15 years (Teste et al. 2011b). The large quantities of accumulated seeds increase the regeneration probability after stand-replacing disturbances.

Pine forests in Canada are currently composed of older age classes than historically recorded, due, in part, to intensive forest protection activities. It is believed that the proportion of older age class trees was a large contributor to the recent record-breaking mountain pine beetle (MPB;

${ }^{1}$ Department of Renewable Resources, University of Alberta, Edmonton, Alberta, T6G 2H1, Canada. * corresponding author's e-mail: nickny@hotmail.com

${ }^{2}$ Environment and Sustainable Resource Development, Government of Alberta, Lac La Biche, Alberta, T0A 2C0, Canada 
Dendroctonus ponderosae Hopkins) outbreak in Canadathe largest in Western North America (Safranyik and Wilson 2006, Raffa et al. 2008, Meddens et al. 2012). Most notably, the beetle is affecting about half of the merchantable lodgepole pine forests of British Columbia and Alberta (Natural Resources Canada 2013) and threatens to expand east into Saskatchewan (Cullingham et al. 2011). This unprecedented MPB outbreak has raised several concerns for forest managers (e.g., Bigler et al. 2005, Negron et al. 2008, Raffa et al. 2008, Simard et al. 2011), namely whether these MPB-killed forests will successfully regenerate naturally with or without fire.

Cone moisture content is an important factor determining cone opening time (Harlow et al. 1964, Hellum and Barker 1980, Johnson and Gutsell 1993) and may potentially affect seed viability (Beaufait 1960). However, it has not been examined whether cone moisture content is determined by internal factors (e.g., the health condition of the tree; cone age) or by external factors (e.g., precipitation). It is also not known how disturbances such as fire impact cone opening and seed viability. Understanding cone moisture after MPB attack is the first step to understanding post-fire regeneration of serotinous pines as it will help determine the energy required to open serotinous cones and the effect it may have on seed viability.

The objectives of this study were to evaluate the interactive effects of MPB-killed trees and cone age on: (1) cone moisture content; (2) moisture exchange; and, (3) time required to open a cone after exposure to heat. We hypothesized that: (1) cones from living trees would have higher moisture content because live trees were likely more vigorous with ability to uptake water; (2) the moisture content of young cones would be constant and that of older cones would vary due to deterioration of the resin seal; and, (3) it would take longer to open cones from living trees because they have higher moisture content. We believe that results of this study will increase the knowledge of cone characteristics on both live and dead lodgepole pine and may lead to further studies evaluating the impact of fire on regeneration after MPB attack.

\section{Materials andMethods Study Area and Sample Collection}

The study area was located in a pure lodgepole pine stand in the Lower Foothills natural sub-region of Alberta (Natural Regions Committee 2006) approximately $70 \mathrm{kms}$ south of

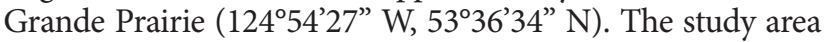
was composed of lodgepole pine aged 100-120 years, with $60 \%$ of the trees killed by mountain pine beetle and the remaining $40 \%$ unaffected at the time of cone collection. The topography was rolling and the forest floor consisted of a thick organic layer with nearly $100 \%$ cover of feather moss (Hylocomium splendens Hedw. and Pleurozium schreberi (Brid.) Mitt.), herbs and shrubs.

Within the study area, we located a site satisfying three criteria: (1) $90 \%$ of the trees were mature; (2) both living and dead trees were present; and, (3) stand age was relatively homogeneous. Three sample stands within the site were selected which were more than one $\mathrm{km}$ and less than five $\mathrm{kms}$ away from each other and located in similar topographic conditions. At each sample stand, three live trees (four trees for one stand due to small cone production) and three MPB- killed trees of similar size were randomly selected and felled, for a total of 19 trees. Height and diameter at breast height $(\mathrm{DBH})$ were recorded and a cross section taken from each at breast height $(1.3 \mathrm{~m})$. The means (standard deviation) of dead and living tree heights were $25.2 \mathrm{~m}( \pm 2.86)$ and $23.3 \mathrm{~m}$ $( \pm 2.64)$, respectively, and diameters $31.2 \mathrm{~cm}( \pm 6.03)$ and 25.2 $\mathrm{cm}( \pm 2.05)$, respectively.

All cones were collected and sampled by age cohort. Where cone ages were unable to be identified, they were not sampled. Aging was completed by first starting at the branch tip and collecting all cones between bud scars (or twig whorls). All cones between a bud scar and a subsequent bud scar were considered to be from the same age cohort. For each tree, cones in the same age cohort were bagged together and each bag marked individually. Cones were transported to the lab and immediately frozen. For dead trees, years of cone production (actual cone age) were identified by determining the year of death according to Speer 2012. A crosssection was sampled from each dead tree at DBH and annual ring growth measured with a microscope and stage micrometer (Velmex system). We developed a master ring chronology using ring growth measurements from live trees. Annual rings of dead trees were cross-dated against the master chronology using the skeleton plot method. The validity of ring data was later confirmed using the COFECHA program (Holmes 1983).

\section{Experimental Design}

Effect of tree mortality and cone age on cone moisture content We randomly selected 128 cones ( 78 from live trees, 83 from dead trees) with lengths of $4.0 \mathrm{~cm}( \pm 0.2 \mathrm{~cm})$ to determine if moisture content was affected by age and mortality. Cones four years old (live $n=21$; dead $n=22$ ), six years (live $n=20$; dead $n=22$ ) and eight years (live $n=21$; dead $n=22$ ) were evaluated. Cone size was restricted in order to minimize potential error due to different surface areas. The wet weight of each cone $\left(M_{W}\right)$ was measured and cones weighed again after drying at $105^{\circ} \mathrm{C}$ for 72 hours to determine dry weight (MD). Moisture content was calculated by the weight of water over dry mass:

$$
\mathrm{MC}=\frac{\left(\mathrm{M}_{\mathrm{W}}-\mathrm{M}_{\mathrm{D}}\right)}{\left(\mathrm{M}_{\mathrm{D}}\right)} \times 100
$$

Cone MC was not normally distributed, so the interactive effects of cone age and tree condition (live or dead) on moisture content was tested using the Kruskal Wallis test. Afterward, the effect of condition on MC was tested for each age class using the Wilcoxon rank sum test.

\section{Effect of tree mortality and cone age on cone moisture exchange}

We also examined if cones exchange moisture and whether the exchange pattern differed by tree condition or cone age. Firstly, we randomly selected five to six cones $4.0 \mathrm{~cm}( \pm 0.2$ $\mathrm{cm}$ ) in size from each age class and tree condition. From the dead trees, five cones were selected from the 4-year-old age class and six from each of the 6- and 8-year-old age classes. Five cones of each age class from live trees were selected for a total of 32 cones (15 live and 17 dead). These cones were taken from the freezer and kept at room temperature for 24 
hours to equilibrate the cone temperature with the surrounding temperature. During this procedure, dew on the surface was removed with a cloth. Each cone was weighed ("Ambient") and then placed in a closed chamber with a desiccant for 72 hours, avoiding direct contact with the cones. Each cone was weighed again immediately after 72 hours incubation ("Desiccant"). As a next step, the cones were placed in a closed chamber for 72 hours with a cup of water (avoiding direct contact) and weighed afterwards ("Humid"). Thereafter, cones were dried at $105^{\circ} \mathrm{C}$ for 72 hours to determine dry weight. Moisture content at each step was calculated using the above equation. We tested if cones significantly absorbed or released moisture using one way repeated ANOVA followed by the Holm-Sidak pairwise multiple comparison test. Finally, cone moisture content was compared between live and dead trees for each age and step using the Wilcoxon rank sum test.

Effect of cone moisture content and cone age on time to open We randomly selected 30 cones from live trees (10 each for 4, 6- and 8-year-old cohorts) and 30 cones from dead trees (10 each for 4-, 6- and 8-year-old cohorts) to examine the relationship between $\mathrm{MC}$ and time required to open cones. Each cone was weighed and placed individually in a convection oven at $180^{\circ} \mathrm{C}$ (Hellum and Barker 1981) and the time taken for the cone to open was recorded. Four measurements were

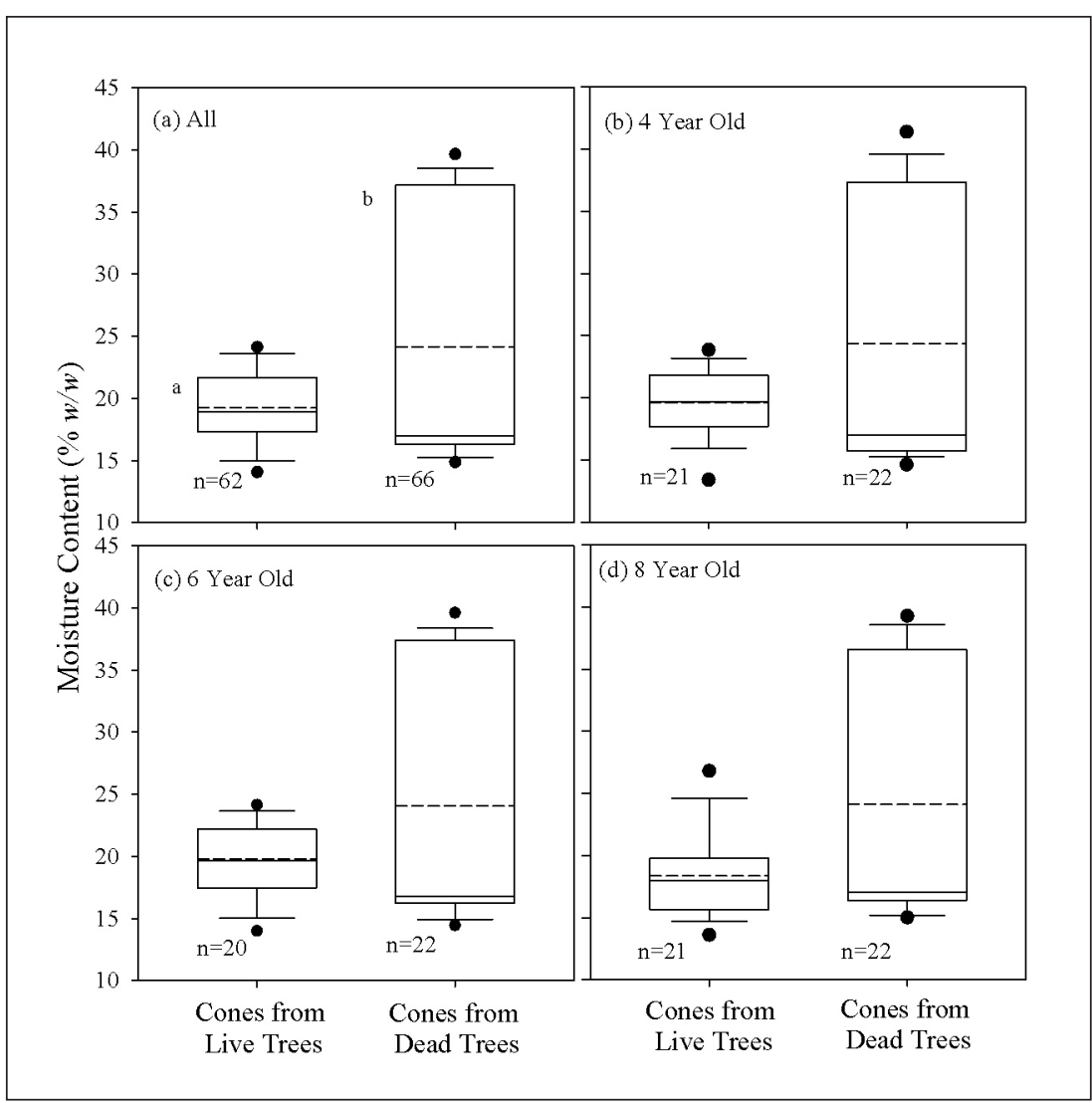

Fig. 1. Moisture content of cones by: a) all ages pooled; b) 4-year-old cones; c) 6-yearold cones; and, d) 8-year-old cones. Dashed bars are the means; solid bars represent 10\%, 25\%, 50\% (median), 75\%, and 90\%. Dots indicate 5\% and 95\% percentile. Letters indicate significant $(p<0.05)$ statistical difference between live and dead groups. made for each cone: (1) the time when the first audible popping sound was heard (First); (2) the time when the poppings became indistinguishable from each other (Start); (3) the time when the popping was distinguishable again (Last); and, (4) the time of the final pop (Finish). The popping sound of five cones was not distinctive and their data were omitted from the analysis: four from the living and one from the dead group. Each cone was weighed before the experiment and all material (i.e., seeds, scales, and cone) collected after the experiment and dried at $105^{\circ} \mathrm{C}$ for 72 hours to determine dry weight. A Pearson correlation analysis was conducted to determine the relationship between the four time measurements and moisture content. We also examined if mortality condition (dead or live) influenced the time taken to open cones for each cone age class using a t-test. All statistical analyses were conducted using SAS (version 9.2) and all statistical differences were determined at $\mathrm{p}<0.05$, unless stated otherwise.

\section{Results}

Effect of tree mortality and cone age on cone moisture content Cone MC of dead trees had a right-skewed distribution while that of living trees showed a normal distribution. Moreover, the median value of the dead trees was always lower than that of the live trees regardless of age class, while the mean MC was always higher for cones from dead trees than from live trees (Fig. 1). The pooled cone MC of the living group $($ mean $=19.24 \%)$ was significantly lower than that of the dead group (mean $=24.17 \%$ ) (Fig.1a). However, the mortality condition did not show any significant influence on cone MC for individual age classes (Fig $1 \mathrm{~b}-\mathrm{d}$ ). Cones from dead trees (standard deviation $=$ 10.50) had higher variation in MC than those from living trees (standard deviation = 3.04) and the mean MC slightly decreased at age eight compared to the other ages.

\section{Effect of tree mortality and cone age on cone moisture exchange}

In the moisture exchange study, cones lost approximately 3\% moisture during the Desiccant process and slightly less moisture was absorbed into the cones during the Humid process, regardless of age class (Fig. 2). Cones from dead trees generally had higher moisture contents than those from live trees, although they were not significantly different. Cones from live trees absorbed and released moisture more actively than those from dead trees, but there was no statistical difference (Fig. 2). The results clearly showed active moisture exchange of serotinous cones, contradictory to our Hypothesis 2 that the resin seal would minimize moisture exchange. 


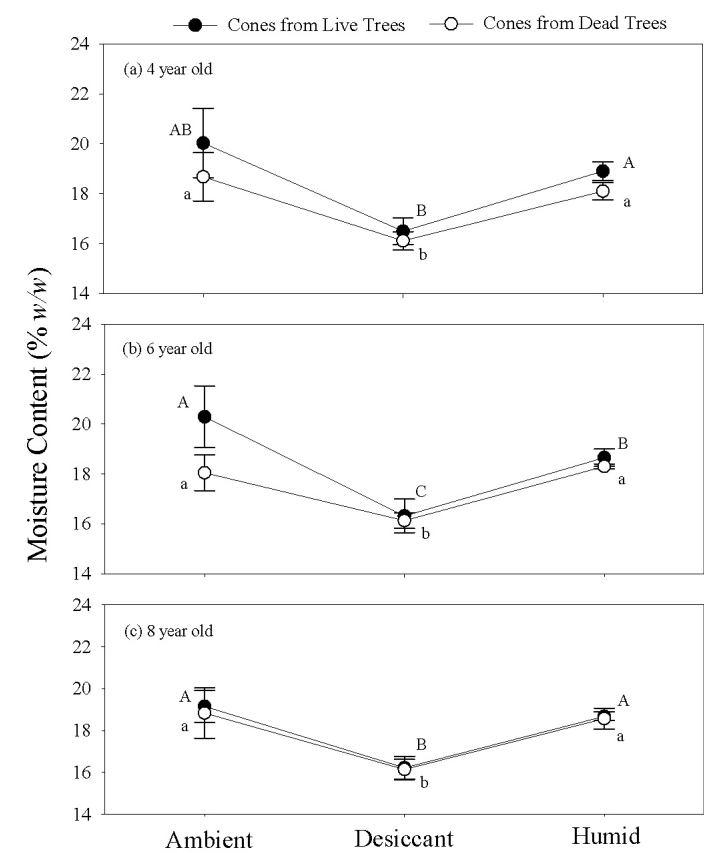

Fig. 2. Exchange of moisture content at three treatments: Ambient, Desiccant and Humid. Letters indicate significant $(p<0.05)$ statistical difference between the three treatments (capital for live; lower case for dead) after one way repeated ANOVA test. Error bars indicate one standard error $(n=55)$.

Effect of cone moisture content and cone age on time to open All "time to break" measurements (i.e., First, Start, Finish, and Last) were positively correlated with each other (Table la-b). For example, when cone A takes more time to make its First popping sound than cone B, it will also take longer for Start, Finish, and Last pop than cone B. Most showed significant correlation with the exception of First versus Finish and First versus Last combinations in the dead group (Table 1b). However, MC only showed significant positive correlation $(p<0.01)$ with Last in cones from dead trees. Surprisingly, MC had a significant negative correlation $(\mathrm{p}<0.01)$ with First. For cones aged four- and six-years-old, it took more time to open cones from dead than from live trees (Fig. 3a-b). The pattern was reversed for 8-year-old cones (Fig. 3c). The MC was always higher in cones from dead than from live trees. This was the same as the first experiment: $15.87 \%, 16.03 \%$, and $16.24 \%$ for cones aged 4,6 , and 8 years sampled from dead trees, respectively, and $17.37 \%, 17.78 \%$, and $16.77 \%$ for cones aged 4,6 , and 8 years sampled from live trees, respectively.

\section{Discussion}

We observed higher mean MC and MC variation in cones of dead trees compared to those of live trees. Considering our results showed active moisture exchange by these serotinous cones, the higher mean $\mathrm{MC}$ and $\mathrm{MC}$ variation would indicate higher atmospheric moisture content and heterogeneity
Table 1. Time (seconds) to open cones and moisture content (MC) from (a) live trees $(n=26$ ) and (b) dead trees ( $n$ is indicated in parenthesis).

(a)

\begin{tabular}{llcccc} 
Variable & First & Start & Finish & Last & MC \\
\hline First & 1.000 & - & - & - & - \\
Start & $0.507^{\star *}$ & 1.000 & - & - & - \\
Finish & $0.391^{\star}$ & $0.912^{\star * *}$ & 1.000 & - & - \\
Last & $0.468^{\star}$ & $0.820^{\star * *}$ & $0.843^{\star * *}$ & 1.000 & - \\
MC & 0.053 & 0.151 & -0.103 & -0.145 & 1.000 \\
\hline
\end{tabular}

(b)

\begin{tabular}{lccccc} 
Variable & First & Start & Finish & Last & MC \\
\hline First & 1.000 & - & - & - & - \\
& $(29)$ & - & - & - & - \\
\multirow{2}{*}{ Start } & $0.504^{* *}$ & 1.000 & - & - & - \\
& $(27)$ & $(27)$ & - & - & - \\
Finish & 0.319 & $0.831^{\star * *}$ & 1.000 & - & - \\
& $(27)$ & $(27)$ & - & - & - \\
\multirow{2}{*}{ Last } & 0.050 & $0.800^{\star * *}$ & $0.902^{* * *}$ & 1.000 & - \\
& $(29)$ & $(27)$ & $(27)$ & - & - \\
MC & $-0.491^{\star *}$ & 0.118 & 0.183 & $0.534^{* *}$ & 1.000 \\
& $(29)$ & $(27)$ & $(27)$ & $(29)$ & $(29)$ \\
\hline
\end{tabular}

First, Start, Finish, and Last indicate time takes to hear the "first pop", "start of main pop", "finish of main pop", and "last pop", respectively.

${ }^{\star},{ }^{* *}$ and ${ }^{* *}$ represent significance at $0.05,0.01$, and 0.001 levels, respectively.

within dead crowns than within live crowns. The higher crown moisture content could be a result of wetter soil resulting from less transpiration. Recent studies in British Columbia also showed that there were higher water tables and wetter soils in MPB-killed stands (Redding et al. 2008). The greater variation in dead crowns may be due to higher heterogeneity of the canopy, resulting in a wider range of light penetration and rain interception.

Hellum (1982) showed that moisture content had a positive relationship with the time taken for cones to open, as those with higher moisture would require more energy to increase the temperature of the cones. Therefore, we expected that it would take more time to open cones from living trees as we had assumed the cones would have higher moisture content (Hypothesis 3). However, our results indicate that cones from dead trees had a higher moisture content and generally required more time to open, thus supporting the results of Hellum (1982) (Fig 3). More specifically, it took longer to open cones from dead trees using all four timing methods for 4-year-old and 6-year-old cones and First for 8-year-old cones. We were particularly puzzled that the pattern was reversed in 8-year-old cones. It was not clear what caused this reversal but we suspected that it may be related to the change in moisture content. Cone MC was approximately $1.5 \%$ different in 4-year-old and 6-year-old cones, but the difference decreased to $0.5 \%$ in 8 -year-old cones. 


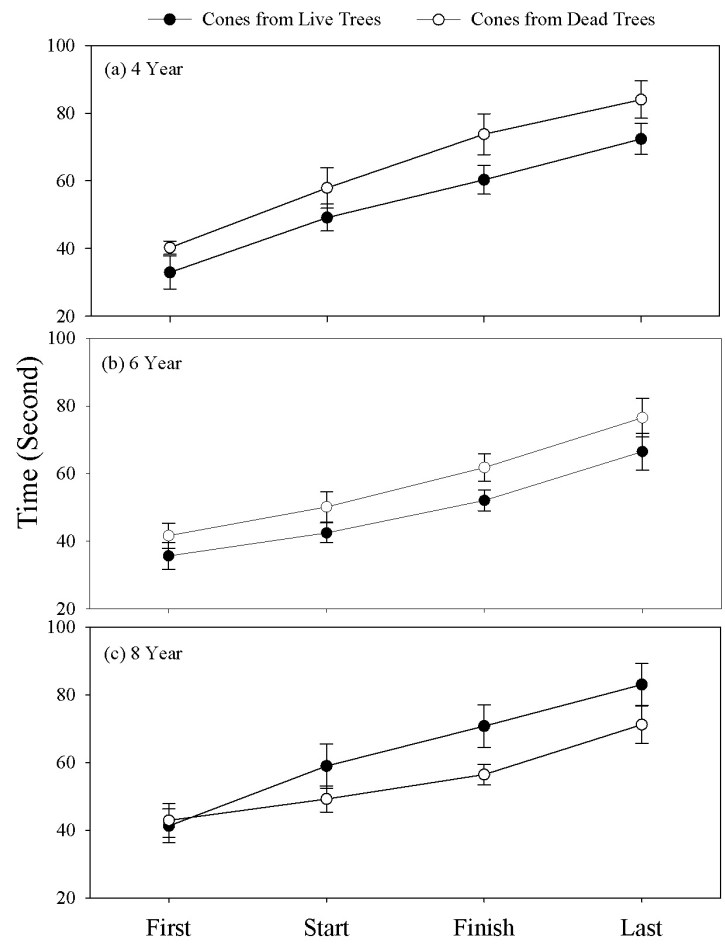

Fig. 3. Time for first to last sounds of cone scale opening. Error bars indicates one standard error $(n=55)$.

Our results imply that the seeds contained within a MPBkilled lodgepole pine may have a better chance to survive a longer residing fire since it takes more time to open the cones, thereby decreasing the opportunity for scorching. Furthermore, if moisture content influences the cone opening timing and heattolerance, as suggested by previous research, the higher moisture variation of cones from dead trees may provide a wider window of survival against various fire intensities and fire residence times.

Our results did not confirm the current understanding of a strong relationship between cone moisture content and time taken to open (Hellum 1982). We only observed a significant positive relationship between Last and cone MC of dead trees, although time to resin break measurements were correlated to each other (Table 1a-b). It was not clear why we did not find a significant influence of cone moisture on resin break. The results suggest that cone $\mathrm{MC}$ is not a dominant driver determining cone opening; there could be other factors associated with this process. Perry and Lotan (1977) showed that the temperature required for cone opening differs among cones of lodgepole pine. Neumann et al. (1964) also reported that both epidermal hairs and resin may play a role in keeping serotinous cones closed. Further studies are needed to clearly understand how the quality and quantity of resin influences the cone opening mechanism and the possible role of epidermal hairs in the mechanism.

\section{Conclusion}

This study is the first to clearly indicate that moisture actively exchanges between atmosphere and serotinous lodgepole pine cones from both live and dead trees. The rate of moisture exchange was similar among cones from both live and dead trees, but it took more time to open cones from dead trees. The results suggest that cone moisture is not the sole driving factor determining the time to open serotinous cones; tree condition and age may also play a role in the process. Cones from dead trees might have a wider window of survival after fire. These results offer a first step to understanding the interactive effects of MPB attack and fire on lodgepole pine regeneration.

\section{Acknowledgements}

This study was funded by the Mountain Pine Beetle Ecology Program of the Foothill Research Institute and Alberta Environment and Sustainable Resource Development. We appreciate the assistance of Professor Vic Lieffers and his early review of the manuscript. Thank you to Vashti Dunham at Weyerhaeuser, Grande Prairie for assistance with site location. A special thanks is given to the Western Partnership for Wildland Fire Science at the University of Alberta.

\section{References}

Beaufait, W. R. 1960. Some effects of high temperatures on the cones and seeds of Jack pine. For. Sci. 6(3): 194-198.

Bigler, C., D. Kulakoswki and T. T. Veblen. 2005. Multiple disturbance interactions and drought interactions and drought influence fire severity in Rocky Mountain subalpine forests. Ecol. 86: 3018-3029.

Clements, F. E. 1910. The life history of lodgepole burnt forests. USDA For. Ser. Bulletin 79. Washington, D.C.

Crossley, D. I. 1956. Fruiting habits of lodgepole pine. Canada Dept. North. Affairs and Nat. Resources Forest Res. Div. Tech. Note 35.

Cullingham, C. I., J. E. Cooke, S. Dang, C. S. Davis, B. J. Cooke and D. W. Coltman. 2011. Mountain pine beetle host-range expansion threatens the boreal forest. Mol. Ecol. 20: 2157-2171.

Harlow, W. M., W. A. Cote Jr. and A. C. Day. 1964. The opening mechanism of pine cone scales. J. For. 62: 538-540.

Hellum, A. K. 1982. Cone moisture and relative humidity effects on seed release from lodgepole pine cones from Alberta. Can. J. For. Res. 12: 102-105.

Hellum, A. K. and N. A. Barker. 1980. Cone moisture content influences seed release in lodgepole pine. Can. J. For. Res. 10(3): 239-244.

Hellum, A. K. and N. A. Barker. 1981. The relationship of lodgepole pine cone age and seed extractability. For. Sci. 27(1): 62-70.

Holmes, R. 1983. Computer-assisted quality control in tree-ring dating and measurement. Tree Ring Bull. 43: 69-75.

Johnson, E. A. and S. L. Gutsell. 1993. Heat budget and fire behavior associated with the opening of serotinous cones in two Pinus species. J. Veg. Sci. 4: 745-750.

Lotan, J. 1976. Cone serotiny-fire relationships in lodgepole pine. Proceedings of the 14th Annual Tall Timbers Fire Ecology Conference and Fire and Land Management Symposium. pp. 267-278. Tall Timbers Research Station. Tallahassee, Florida.

Meddens, A. J. H., J. A. Hicke and C. A. Ferguson. 2012. Spatiotemporal patterns of observed bark beetle-caused tree mortality in British Columbia and the western United States. Ecol. Appl. 22: 1876-1891. 
Natural Regions Committee. 2006. Natural Regions and Subregions of Alberta. Compiled by D. J. Downing and W.W. Pettapiece. Government of Alberta. Pub. No. T/852.

Natural Resources Canada. 2013. Mountain pine beetle (factsheet). Available from http://www.nrcan.gc.ca/forests/insects-diseases/13397 [accessed 20 October 2013].

Negron, J. F., B. J. Bentz, C. J. Fettig, N. Gillette, E. M. Hansen, J. L. Hays, R. G. Kelsey, J. E. Lundquist, A. M. Lynch, R. A. Progar and S. J. Seybold. 2008. U.S. Forest Service bark beetle research in the western United States: Looking toward the future. J. For. 106: 325-331.

Neumann, F. P, T. Schantz-Hansen and L. W. Rees. 1964. Cone scale movements of Jack pine (Pinus banksiana Lamb.). Minnesota Forestry Notes \#142.

Perry, D. A. and J. E. Lotan. 1977. Opening temperatures in serotinous cones in lodgepole pine. USDA FSRN INT-228.

Raffa, K. F., B. H. Aukema, B. J. Bentz, A. L. Carroll, J. A. Hicke, M. G. Turner and W. H.

Romme. 2008. Cross-scale drivers of natural disturbances prone to anthropogenic amplification: The dynamics of bark beetle eruptions. BioSci. 58(6): 501-517.

Redding, T., R. Winkler, P. Teti, D. Spittlehouse, S. Boon, J. Rex, S. Dubé, R. D. Moore, A. Wei, M. Carver, M. Schnorbus, L. Reese-
Hansen, and S. Chatwin. 2008. Mountain pine beetle and watershed hydrology. In Mountain Pine Beetle: From Lessons Learned to Community-based Solutions. Conference Proceedings, June 10-11, 2008. BC J. Ecosyst. Manage. 9(3): 33-50.

Safranyik, L. and B. Wilson. 2006. The mountain pine beetle: A synthesis of biology, management, and impacts on lodgepole pine. Pacific Forestry Centre, Canadian Forest Service, Natural Resources Canada, Victoria, Canada.

Simard, M., W. H. Romme, J. M. Griffin and M. G. Turner. 2011. Do mountain pine beetle outbreaks change the probability of active crown fire in lodgepole pine forests? Ecol. Monogr. 81: 3-24.

Speer, J. H. 2012. Fundamentals of Tree Ring Research. The University of Arizona Press. 324 pp.

Teste, F. P., V. J. Lieffers and S. M. Landhausser. 2011a. Seed release in serotinous lodgepole pine forests after mountain pine beetle outbreak. Ecol. appl. 21(1): 150-162.

Teste, F. P., V. J. Lieffers and S. M. Landhausser. 2011b. Viability of forest floor and canopy seed banks in Pinus contorta var. latifolia (Pinaceae) forests after a mountain pine beetle outbreak. Am. J. Bot. 98(4): 1-8.

Tower, G. E. 1909. A study of the reproductive characteristics of lodgepole pine. Proc. Soc. Am. For. 4: 84-106. 